\title{
Treatment for alzheimer's disease: The present and future
}

\author{
Cheng Wei ${ }^{1, *}$ \\ ${ }^{1}$ Case Western Reserve University, Cleveland, OH, 44122, America
}

\begin{abstract}
Alzheimer's disease (AD) is a growing global health crisis, however, there are currently very few effective treatments for it. All existent treatments serve only to ameliorate the symptoms of AD instead of curing it. With the deepening of the disease pathology in recent years, there have been many studies and clinical trials that aim to discover new disease-modifying therapies. Nanoparticle drug delivery platform is a promising path for its high penetration rate across the blood brain barrier, while heat shock proteins provide a new strategy to target the mutant proteins that cause AD. These novel therapies may help us better treat and potentially cure $\mathrm{AD}$, but many of them are still in their early stage of development and their side effects are still unknown. A truly effective treatment for AD is still years ahead.
\end{abstract}

\section{Introduction}

Alzheimer's disease (AD) is a neurodegenerative disease that impairs the brain's cognitive and memory function in the elderly population. There are several proposed pathologies for $\mathrm{AD}$, including neurofibrillary tangles (NFTs) formed by hyper-phosphorylated tau protein and aggregation of extracellular proteins like $\beta$-amyloid (A $\beta)$ peptide. (Fig. 1) [1] The specifics of how these abnormalities lead to the symptoms of $\mathrm{AD}$ are still unclear, but it is theorized that the insoluble protein oligomers can cause an inflammatory effect, and the subsequent oxidative damage kills many neurons surrounding the aggregated proteins. [2] Even though genetics can directly affect how proteins behave, it is being proven in numerous studies that ageing, environmental, and dietary risk factors may contribute the most when it comes to developing AD. An unhealthy diet with high fat and high sugar content, air pollution, and poor sleeping are common risk factors found in $\mathrm{AD}$ cases. [3,4] Among these, ageing plays the most significant role. There is currently no treatment that targets these mechanisms and provides a cure for $\mathrm{AD}$. All the existing therapies only seek to mitigate the symptoms and prolong the patients' life. [5] This article will review the current therapies for $\mathrm{AD}$ and discuss some of the future treatments currently being proposed or developed..

\section{Current Treatments}

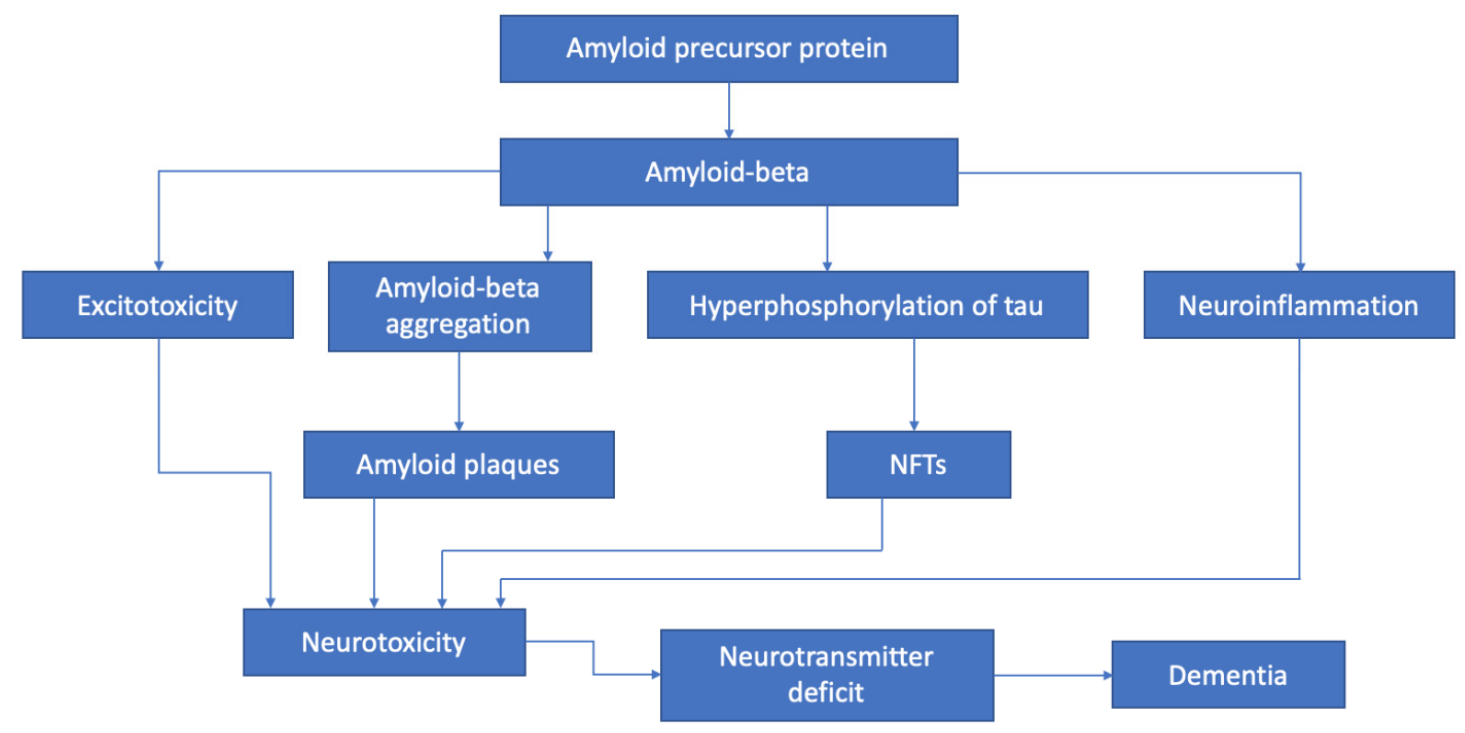

Fig.1. Aetiology of Alzheimer's disease. 


\subsection{Cholinesterase Inhibitors}

One of the major hypotheses for why patients with $\mathrm{AD}$ have a lowered cognitive function is the cholinergic hypothesis. It is theorized that impaired brain functions are caused by reducing acetylcholine's secretion (ACh). Ach is a neural transmitter that plays a crucial role in the passing of signals across the synapses. In the brain, Ach is responsible for numerous physiological processes such as memory, learning, and attention. In this theory, the decreased level of Ach in the brain can explain the cognitive dysfunction that comes with AD. Thus, inhibiting acetylcholinesterase (AChE) to increase ACh's level becomes a feasible solution to mitigate the symptoms. AChE is the main enzyme that breaks down ACh. By introducing acetylcholinesterase inhibitors (AChEI) to the brain, ACh's degradation is decreased, and $\mathrm{ACh}$ can accumulate and restore normal cognitive function. [6] Tacrine was the first AChEI to be approved by the FDA for clinical treatment of AD. However, Tacrine met immediate setbacks after its introduction to the market. It had severe side effects, including hepatoxicity, and its therapeutic effect was not ideal. [7] Several other AChEIs were also developed and introduced to the market after the failure of Tacrine, such as donepezil and galantamine. These products exhibit low cytotoxicity and increased therapeutic efficacy, and they are still being used for the symptomatic treatment of $\mathrm{AD}[8]$.

\subsection{N-methyl D-aspartate Receptor (NMDAR) Antagonists}

NMDAR, when activated, allows the influx of $\mathrm{Ca} 2+$, which eventually leads to the activation of gene activation necessary for the formation of long-term potentiation (LTP). It is theorized that the overactivation of NMDAR in patients with AD can cause a critically elevated level of $\mathrm{Ca} 2+$ inside the neurons and consequently leads to overstimulation of glutamate. Glutamate is the main excitatory amino acid in the CNS, and the constant stimulation eventually causes excitotoxicity and cell death. NMDAR antagonists can block NMDAR's functional site and control the level of activation. So far, memantine is the only NMDAR antagonist approved by the FDA to be used for clinical treatment of $\mathrm{AD}$. It is a low-affinity uncompetitive antagonist, and it is proven to be effective in blocking NMDAR without interfering with normal synaptic functions. Memantine is usually used to treat severe AD and often used alongside AChEI. [9-12]

\section{Future Treatments}

\subsection{Nanoparticle Delivery Systems}

Nanoparticle drug and gene delivery therapies for $\mathrm{AD}$ are gaining significant attention because of their high therapeutic efficacy. Traditional drug delivery platforms (oral, injection) are mostly passive drug delivery methods and thus make drug difficult to get to the brain, especially with the protection of the blood-brain-barrier (BBB). BBB is a layer of endothelial cells that surrounds the central nervous system (CNS). It is highly selective and tightly regulates the substances that can cross into and out of the CNS. [13] Hydrophobic molecules can pass the BBB with relative ease, and hydrophilic molecules can only cross the BBB with the aid of special transporters. Because of this, a popular candidate for nanoparticle drug delivery inside the BBB is a liposome. The liposome is a hydrophobic, biocompatible, and biodegradable material, and it is one of the most common materials used for nanoparticle drug delivery platforms. [14]

\subsubsection{Aß-targeting Liposome Particles}

One example of nanoparticle drug delivery therapy for $\mathrm{AD}$ is liposome particles multi functionalized with phosphatidic acid (PA) and modified apolipoprotein $\mathrm{E}$ (mApoE). PA has been proven to bind to A $\beta$ oligomers and disassemble them for plasma excretion. $\mathrm{mApoE}$ is a ligand that can pair with multiple receptors present on the BBB. [15-16] The therapy is still under development, but preliminary animal studies have shown that the AD mice treated with this therapy exhibited better cognitive function recovery [17]

\subsubsection{Liposomal mApoE2 Gene Delivery System}

Liposomal gene delivery is also a viable treatment method for $\mathrm{AD}$. It is recently discovered that ApoE2 is beneficial for $\mathrm{AD}$ prevention for its role in clearing $\mathrm{A} \beta$ peptide aggregation. The isoform ApoE4, however, can contribute to the progression of AD. Thus, a liposomal gene delivery platform is developed to deliver ApoE2 plasmid DNA (pDNA) into the neuronal cells to stimulate more ApoE2 production. The pDNA is enclosed inside the particle, and the particle surface is functionalized with penetratin (Pen) and glut-1 targeting ligand mannose (MAN). (Fig. 2) MAN can help the particle target and cross the BBB, while Pen aid in cellular internalization. The in vitro studies showed that the cells treated with this particle exhibited high ApoE2 expression, which can be a promising treatment in the future. $[18,19]$ 


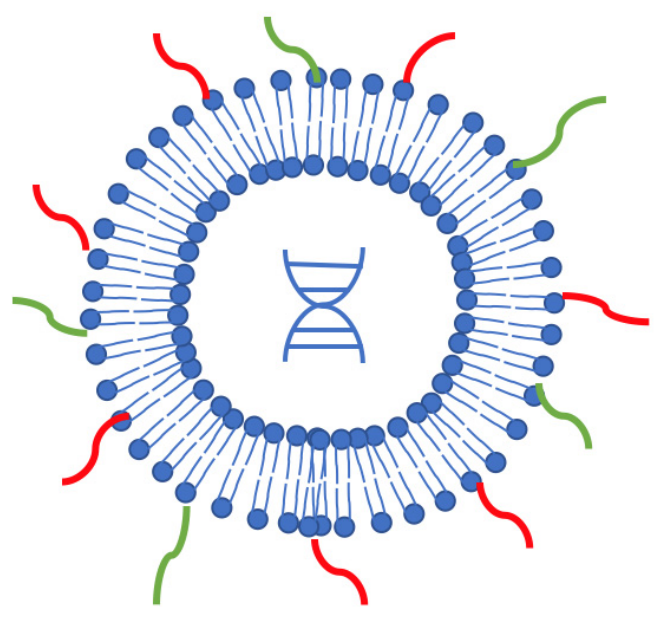

Phospholipid

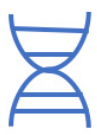

ApoE2 Gene

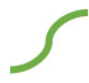

Penetratin

glut-1 targeting ligand mannose

Fig. 2. Schematics of the liposomal mApoE2 nanoparticle

\subsection{Heat Shock Proteins (Hsps)}

Heat shock proteins are intracellular proteins that protect cells from elevated temperatures. They do so by binding to and prevent other proteins from misfolding under heat. Similarly, most neurodegenerative diseases, including $\mathrm{AD}$, are caused by protein misfolding and aggregation. So, we might be able to harvest the unique function of Hsps and use them to target the key proteins in AD. There are already several Hsps that can prevent A $\beta$ peptide and tau misfolding. [20]

\section{2. $1 \mathrm{Hsp} 60$}

Hsp60 is a large heat shock protein that is critical in mitochondrial protein folding. How it participates in the disease progression of $\mathrm{AD}$ is not yet clear. Still, it is theorized that it could be overexpressed by active microglia and lead to neuronal cell death by elevated pro-inflammatory factors. Thus, inhibiting the expression of Hsp60 and activated microglia might be a potential solution for treating AD. Mizoribine and pyrazolopyrimidine EC3016 are both examples of molecules that can inhibit Hsp60. They can bind to the ATPase active site on Hsp60 and prevent the protein from functioning. But the pharmacology of this theory is still unclear and needs more investigation. [20]

\section{2. $2 \mathrm{Hsp} 70$}

Hsp70 has been proven in a recent study to bind to $A$ 42 and prevent self-aggregation. In the animal study, Hsp70 exhibited two functions: protecting neurons from A $\beta 42$ neurotoxicity and synaptic loss. Hsp70 functions by activating microglia, insulin-degrading enzyme, and tumor growth factor- $\beta 1$ (TGF- $\beta 1$ ), which can degrade A $\beta$ peptide. Hsp70 can also bind to tau and its mutant form to prevent aggregation. [21] By examining $\mathrm{AD}$ brain tissue samples, an overexpression of Hsp70 was observed, and there could be a connection between this and the activated glia cells and stressed neurons. Hsp70 could also be associated with extracellular deposits in
AD. Several anticancer drugs, which target Hsp70's ATP-binding site, could be used to treat AD. YM-01 is an excellent Hsp70 inhibiting compound. It binds to Hsp70 and prevents proliferation. It was developed as a derivative of MKT-077, a similar compound but with high toxicity and low bioavailability. [22-24]

\subsubsection{Hsp90}

Hsp90 is another large heat shock protein that is thought to take part in $\mathrm{AD}$ 's disease progression. Hsp90 regulates tau phosphorylation and dephosphorylation. Inhibition of Hsp90 leads to a decrease in tau kinase activity and tau phosphorylation. Like Hsp70, inhibitors of Hsp90 are also previous anticancer drugs. Animals studies have identified several Hsp70 inhibitors that worked in mouse models. 17-AAG is one of the most promising one among them. It is a derivative of geldanamycin (GA) but with lower cytotoxicity and better bioavailability. Pochoxime $\mathrm{C}$ is also an Hsp70 which gained attention for its safety and therapeutic efficacy in animal studies. From these studies, Hsp has been proven to be promising candidates for AD treatment. [25-27]

\subsection{Nutraceuticals}

Natural compounds, mostly from plants, have been used to treat diseases for thousands of years, and recently researchers are turning to these products for neurodegenerative diseases. Some nature-sourced molecules have shown therapeutic effects and are in clinical trials for AD. Below, we will introduce several nutraceuticals from traditional Chinese folk medicine.

\subsubsection{Allium Compounds}

Allium compounds are abundant in garlic (Allium sativum), a vegetable that is cultivated around the world. It is widely used in cooking, but it has also been used to treat cardiovascular diseases in China for 3000 years. [28] Allium compounds mainly consist of diallyl sulfide, sallyl-1-cysteine sulfoxides (Allin), S-allyl-1-cysteine and allicin (diallyl thiosulphate). [29] These molecules are 
organo-sulfurous and contribute to the unique smell and taste of fresh garlic. From many studies, Allium compounds have shown anti-inflammatory, antitumor, cardioprotective, antioxidant properties. [30-32] As mentioned above, AD is mainly caused by misfolded tau protein, which aggregates and leads to the upregulation of proinflammatory agents, activating the NF-K $\beta$ cascade and downregulating ERK, CRED, and Akt pathways. But one of the Allium compounds, s-allyl cysteine (SAC), has been proven to downregulate the NF-K $\beta$ cascade thus slowing down AD progression. $[33,34]$ In addition, SAC has been proven to repair neuronal damage and aid in memory function remediation. [35,36] Allium compounds also have little side effects and are considered generally safe by the FDA.

\subsubsection{Turmeric}

Turmeric (Curcuma longa) is a plant that mainly grows in Southeast Asia. It is mostly consumed as a spice, but it has also been used as a medicine for thousands of years. Its active compound, curcumin, has long been identified as a strong antioxidant, anti-inflammatory, and antitumor agent. [37] Recently, curcumin has become a rising star in the field of $\mathrm{AD}$ treatment for its antiamyloid properties. [38] In several studies, curcumin has shown the effect of inhibiting $A$ production and aggregation while increasing $A \beta$ clearance. In addition to its anti- $A \beta$ amyloid property, curcumin also serves as an anti-inflammatory compound that reduces the inflammation caused by tauopathy. Curcumin can inhibit the enzyme cyclooxygenase (Cox-2),5- Lipoxygenase(5Lox), the enzyme responsible for prostaglandin synthesis, and NF-kB, a neuroinflammatory marker. $[39,40]$

\subsubsection{Ginseng}

Ginseng (Panax ginseng) is another herb that has been used as a medicine for thousands of years. Ginsenosides, the active compounds of ginseng, have shown neuroprotective and memory enhancement effects. [41] Some ginsenosides can prevent A $\beta$ plaque formation by inhibiting beta secretase 1 (BACE1), an enzyme that is critical for $A \beta$ formation. [42] As mentioned above, one of the major current treatments for $\mathrm{AD}$ is AChEIs, ginsenosides Rb1, Rb2, Rc, Re, Rg1, and Rg3 have also shown AChE inhibiting properties. [43] $\mathrm{Rg} 2$ can protect neurons from oxidative stress by reducing the $\mathrm{Ca} 2+$ and reactive oxidative species (ROS) levels. Rb1 and Rb5 can inhibit NF-k $\beta$ and reduce the expression of antiinflammatory factors like IL-1B, IL-6, and TNF- a . [44]

\section{Conclusion}

As the number of $\mathrm{AD}$ cases around the world continues to rise, it has become a global health issue that requests increasing effort to find a solution. However, despite the massive amount of time and capital that have been spent, the current clinical treatments still only provide symptomatic amelioration. The primary reason behind it is that we still do not fully understand the pathology of AD. There are many explicit theories, but the deeper we dig, the more complex the disease becomes. Cholinesterase inhibitors and NMDA antagonists like galantamine and memantine work well to enhance patients' memory, but there is no way to pause the disease progression. Fortunately, as more details of AD pathology are being uncovered, researchers are finding alternative ways to target $A B$ and tau pathologies. Liposome nanoparticles carrying mApoE and phosphatidic acid can cross the BBB and breakdown A $\beta$ plaques, while the particle can also carry ApoE2 gene to increase the expression of ApoE2 and achieve the same effect. Heat shock proteins are also promising candidates that aid in protein function maintenance. Nutraceuticals from traditional Chinese medicine are also attracting much attention for their great potentials in treating AD. In conclusion, the key to treating $\mathrm{AD}$ lies behind the full understanding of the disease. The novel treatments that target $A \beta$ and tau pathologies may be able to stop the disease progression instead of slowing it down.

\section{Acknowledgement}

First of all, I would like to show gratitude to my professors in my university for their great guidance in every stage of the writing of this paper. Further, I would like to thank all my friends and family members who supported me. Without their help, this thesis could not have been completed.

\section{References}

1. Lane CA, Hardy J, Schott JM. Alzheimer's disease. Eur J Neurol. 2018 Jan;25(1):59-70. doi: 10.1111/ene.13439. Epub 2017 Oct 19. PMID: 28872215.

2. Moreira PI, Siedlak SL, Aliev G, Zhu X, Cash AD, Smith MA, Perry G. Oxidative stress mechanisms and potential therapeutics in Alzheimer disease. $\mathrm{J}$ Neural Transm (Vienna). 2005 Jul;112(7):921-32. doi: 10.1007/s00702-004-0242-8. Epub 2004 Dec 7. PMID: 15583960.

3. Dosunmu R, Wu J, Basha MR, Zawia NH. Environmental and dietary risk factors in Alzheimer's disease. Expert Rev Neurother. 2007 Jul;7(7):887-900. doi: 10.1586/14737175.7.7.887. PMID: 17610395.

4. Van Gastel J, Leysen H, Boddaert J, van Genechten L, Luttrell LM, Martin B, Maudsley S. Agingrelated modifications to $G$ protein-coupled receptor signaling diversity. Pharmacol Ther. 2020 Dec 11:107793. doi: 10.1016/j.pharmthera.2020.107793. Epub ahead of print. PMID: 33316288.

5. Li J, Du Q, Li N, Du S, Sun Z. Alpiniae oxyphyllae Fructus and Alzheimer's disease: An update and current perspective on this traditional Chinese medicine. Biomed Pharmacother. 2020 Dec 
29;135:111167. doi: 10.1016/j.biopha.2020.111167. Epub ahead of print. PMID: 33383373.

6. Marucci G, Buccioni M, Ben DD, Lambertucci C, Volpini R, Amenta F. Efficacy of acetylcholinesterase inhibitors in Alzheimer's disease. Neuropharmacology. 2020 Oct 6:108352. doi: 10.1016/j.neuropharm.2020.108352. Epub ahead of print. PMID: 33035532.

7. Singh R, Sadiq NM. Cholinesterase Inhibitors. 2020 May 16. In: StatPearls [Internet]. Treasure Island (FL): StatPearls Publishing; 2020 Jan-. PMID: 31335056.

8. Bautista-Aguilera ÓM, Ismaili L, Iriepa I, DiezIriepa D, Chabchoub F, Marco-Contelles J, Pérez M. Tacrines as Therapeutic Agents for Alzheimer's Disease. V. Recent Developments. Chem Rec. 2020 Nov 10. doi: 10.1002/tcr.202000107. Epub ahead of print. PMID: 33169934.

9. Liu J, Chang L, Song Y, Li H, Wu Y. The Role of NMDA Receptors in Alzheimer's Disease. Front Neurosci. $\quad 2019 \quad$ Feb 8;13:43. doi: 10.3389/fnins.2019.00043. PMID: 30800052; PMCID: PMC6375899.

10. Uddin MS, Al Mamun A, Kabir MT, Ashraf GM, Bin-Jumah MN, Abdel-Daim MM. Multi-Target Drug Candidates for Multifactorial Alzheimer's Disease: AChE and NMDAR as Molecular Targets. Mol Neurobiol. 2021 Jan;58(1):281-303. doi: 10.1007/s12035-020-02116-9. Epub 2020 Sep 15. PMID: 32935230.

11. Agatonovic-Kustrin S, Kettle C, Morton DW. A molecular approach in drug development for Alzheimer's disease. Biomed Pharmacother. 2018 Oct;106:553-565. doi: 10.1016/j.biopha.2018.06.147. Epub 2018 Jul 11. PMID: 29990843.

12. Geerts H, Grossberg GT. Pharmacology of acetylcholinesterase inhibitors and N-methyl-Daspartate receptors for combination therapy in the treatment of Alzheimer's disease. J Clin Pharmacol. 2006 Jul;46(7 Suppl 1):8S-16S. doi: 10.1177/0091270006288734. PMID: 16809810.

13. Daneman R, Prat A. The blood-brain barrier. Cold Spring Harb Perspect Biol. 2015 Jan 5;7(1):a020412. doi: 10.1101/cshperspect.a020412. PMID: 25561720; PMCID: PMC4292164.

14. Ross C, Taylor M, Fullwood N, Allsop D. Liposome delivery systems for the treatment of Alzheimer's disease. Int J Nanomedicine. 2018 Dec 12;13:85078522. doi: 10.2147/IJN.S183117. PMID: 30587974; PMCID: PMC6296687.

15. Gobbi M, Re F, Canovi M, Beeg M, Gregori M, Sesana S, Sonnino S, Brogioli D, Musicanti C, Gasco P, Salmona M, Masserini ME. Lipid-based nanoparticles with high binding affinity for amyloidbeta1-42 peptide. Biomaterials. 2010

Sep;31(25):6519-29. doi:

10.1016/j.biomaterials.2010.04.044. PMID: 20553982.
16. Zhao N, Liu CC, Qiao W, Bu G. Apolipoprotein E, Receptors, and Modulation of Alzheimer's Disease. Biol Psychiatry. 2018 Feb 15;83(4):347-357. doi: 10.1016/j.biopsych.2017.03.003. Epub 2017 Mar 14. PMID: 28434655; PMCID: PMC5599322.

17. Balducci C, Mancini S, Minniti S, La Vitola P, Zotti M, Sancini G, Mauri M, Cagnotto A, Colombo L, Fiordaliso F, Grigoli E, Salmona M, Snellman A, Haaparanta-Solin M, Forloni G, Masserini M, Re F. Multifunctional liposomes reduce brain $\beta$-amyloid burden and ameliorate memory impairment in Alzheimer's disease mouse models. J Neurosci. 2014 Oct 15;34(42):14022-31. doi: 10.1523/JNEUROSCI. 0284-14.2014. PMID: 25319699; PMCID: PMC4198543.

18. Serrano-Pozo A, Das S, Hyman BT. APOE and Alzheimer's disease: advances in genetics, pathophysiology, and therapeutic approaches. Lancet Neurol. 2021 Jan;20(1):68-80. doi: 10.1016/S1474-4422(20)30412-9. PMID: 33340485.

19. Arora S, Layek B, Singh J. Design and Validation of Liposomal ApoE2 Gene Delivery System to Evade Blood-Brain Barrier for Effective Treatment of Alzheimer's Disease. Mol Pharm. 2020 Sep 16. doi: 10.1021/acs.molpharmaceut.0c00461. Epub ahead of print. PMID: 32787268.

20. Wilhelmus MM, de Waal RM, Verbeek MM. Heat shock proteins and amateur chaperones in amyloidBeta accumulation and clearance in Alzheimer's disease. Mol Neurobiol. 2007 Jun;35(3):203-16. doi: 10.1007/s12035-007-0029-7. PMID: 17917109; PMCID: PMC2039847.

21. Martín-Peña A, Rincón-Limas DE, Fernandez-Fúnez P. Engineered Hsp70 chaperones prevent $\mathrm{A} \beta 42-$ induced memory impairments in a Drosophila model of Alzheimer's disease. Sci Rep. 2018 Jul 2;8(1):9915. doi: 10.1038/s41598-018-28341-w. PMID: 29967544; PMCID: PMC6028656.

22. Repalli J, Meruelo D. Screening strategies to identify HSP70 modulators to treat Alzheimer's disease. Drug Des Devel Ther. 2015 Jan 7;9:321-31. doi: 10.2147/DDDT.S72165. PMID: 25609918; PMCID: PMC4294646.

23. Li X, Shao H, Taylor IR, Gestwicki JE. Targeting Allosteric Control Mechanisms in Heat Shock Protein 70 (Hsp70). Curr Top Med Chem. 2016;16(25):2729-40. doi: 10.2174/1568026616666160413140911. PMID: 27072701; PMCID: PMC5502483.

24. Abisambra J, Jinwal UK, Miyata Y, Rogers J, Blair L, Li X, Seguin SP, Wang L, Jin Y, Bacon J, Brady S, Cockman M, Guidi C, Zhang J, Koren J, Young ZT, Atkins CA, Zhang B, Lawson LY, Weeber EJ, Brodsky JL, Gestwicki JE, Dickey CA. Allosteric heat shock protein 70 inhibitors rapidly rescue synaptic plasticity deficits by reducing aberrant tau. Biol Psychiatry. 2013 Sep 1;74(5):367-74. doi: 10.1016/j.biopsych.2013.02.027. Epub 2013 Apr 19. PMID: 23607970; PMCID: PMC3740016. 
25. Bohush A, Bieganowski P, Filipek A. Hsp90 and Its Co-Chaperones in Neurodegenerative Diseases. Int J Mol Sci. 2019 Oct 9;20(20):4976. doi: 10.3390/ijms20204976. PMID: 31600883; PMCID: PMC6834326.

26. Luo W, Rodina A, Chiosis G. Heat shock protein 90: translation from cancer to Alzheimer's disease treatment? BMC Neurosci. 2008 Dec 3;9 Suppl 2(Suppl 2):S7. doi: 10.1186/1471-2202-9-S2-S7. PMID: 19090995; PMCID: PMC2604891.

27. Wang B, Liu Y, Huang L, Chen J, Li JJ, Wang R, Kim E, Chen Y, Justicia C, Sakata K, Chen H, Planas A, Ostrom RS, Li W, Yang G, McDonald MP, Chen R, Heck DH, Liao FF. A CNS-permeable Hsp90 inhibitor rescues synaptic dysfunction and memory loss in APP-overexpressing Alzheimer's mouse model via an HSF1-mediated mechanism. Mol Psychiatry. 2017 Jul;22(7):990-1001. doi: 10.1038/mp.2016.104. Epub 2016 Jul 26. PMID: 27457810 ; PMCID: PMC5323357.

28. Sultan MT, Butt MS, Qayyum MM, Suleria HA. Immunity: plants as effective mediators. Crit Rev Food Sci Nutr. 2014;54(10):1298-308. doi: 10.1080/10408398.2011.633249. PMID: 24564587.

29. Butt MS, Sultan MT, Butt MS, Iqbal J. Garlic: nature's protection against physiological threats. Crit Rev Food Sci Nutr. 2009 Jun;49(6):538-51. doi: 10.1080/10408390802145344. PMID: 19484634.

30. Borlinghaus J, Albrecht F, Gruhlke MC, Nwachukwu ID, Slusarenko AJ. Allicin: chemistry and biological properties. Molecules. 2014 Aug 19;19(8):12591-618. doi:

10.3390/molecules190812591. PMID: 25153873; PMCID: PMC6271412.

31. Kumar R, Chhatwal S, Arora S, Sharma S, Singh J, Singh N, Bhandari V, Khurana A. Antihyperglycemic, antihyperlipidemic, antiinflammatory and adenosine deaminase- lowering effects of garlic in patients with type 2 diabetes mellitus with obesity. Diabetes Metab Syndr Obes. 2013;6:49-56. doi: 10.2147/DMSO.S38888. Epub 2013 Jan 19. PMID: 23378779; PMCID: PMC3554227.

32. Zhu JW, Chen T, Guan J, Liu WB, Liu J.

Neuroprotective effects of allicin on spinal cord ischemia-reperfusion injury via improvement of mitochondrial function in rabbits. Neurochem Int. 2012 Oct;61(5):640-8. doi:

10.1016/j.neuint.2012.06.021. Epub 2012 Jun 29. PMID: 22750272.

33. Lin GH, Lee YJ, Choi DY, Han SB, Jung JK, Hwang BY, Moon DC, Kim Y, Lee MK, Oh KW, Jeong HS, Leem JY, Shin HK, Lee JH, Hong JT. Anti-amyloidogenic effect of thiacremonone through anti-inflamation in vitro and in vivo models. J Alzheimers Dis. 2012;29(3):659-76. doi: 10.3233/JAD-2012-111709. PMID: 22297647.

34. Arunkumar R, Sharmila G, Elumalai P, Senthilkumar K, Banudevi S, Gunadharini DN,
Benson CS, Daisy P, Arunakaran J. Effect of diallyl disulfide on insulin-like growth factor signaling molecules involved in cell survival and proliferation of human prostate cancer cells in vitro and in silico approach through docking analysis. Phytomedicine. 2012 Jul 15;19(10):912-23. doi: 10.1016/j.phymed.2012.04.009. Epub 2012 Jun 26. PMID: 22739413.

35. Lin $\mathrm{X}, \mathrm{Yu} \mathrm{S}$, Chen $\mathrm{Y}, \mathrm{Wu}$ J, Zhao J, Zhao $\mathrm{Y}$. Neuroprotective effects of diallyl sulfide against transient focal cerebral ischemia via anti-apoptosis in rats. Neurol Res. 2012 Jan;34(1):32-7. doi: 10.1179/1743132811Y.0000000054. PMID: 22196859.

36. Chauhan NB, Sandoval J. Amelioration of early cognitive deficits by aged garlic extract in Alzheimer's transgenic mice. Phytother Res. 2007 Jul;21(7):629-40. doi: 10.1002/ptr.2122. PMID: 17380553.

37. Skrzypek A, Matysiak J, Karpińska M, Czarnecka K, Kręcisz P, Stary D, Kukułowicz J, Paw B, Bajda M, Szymański P, Niewiadomy A. Biological evaluation and molecular docking of novel 1,3,4-thiadiazoleresorcinol conjugates as multifunctional cholinesterases inhibitors. Bioorg Chem. 2021 Jan 5;107:104617. doi: 10.1016/j.bioorg.2020.104617. Epub ahead of print. PMID: 33444983.

38. Garcia-Alloza M, Borrelli LA, Rozkalne A, Hyman BT, Bacskai BJ. Curcumin labels amyloid pathology in vivo, disrupts existing plaques, and partially restores distorted neurites in an Alzheimer mouse model. J Neurochem. 2007 Aug;102(4):1095-104. doi: 10.1111/j.1471-4159.2007.04613.x. Epub 2007 Apr 30. PMID: 17472706.

39. Park SY, Kim DS. Discovery of natural products from Curcuma longa that protect cells from betaamyloid insult: a drug discovery effort against Alzheimer's disease. J Nat Prod. 2002 Sep;65(9):1227-31. doi: 10.1021/np010039x. PMID: 12350137.

40. Biswas SK, McClure D, Jimenez LA, Megson IL, Rahman I. Curcumin induces glutathione biosynthesis and inhibits NF-kappaB activation and interleukin-8 release in alveolar epithelial cells: mechanism of free radical scavenging activity. Antioxid Redox Signal. 2005 Jan-Feb;7(1-2):32-41. doi: 10.1089/ars.2005.7.32. PMID: 15650394.

41. Christensen LP. Ginsenosides chemistry, biosynthesis, analysis, and potential health effects. Adv Food Nutr Res. 2009;55:1-99. doi: 10.1016/S1043-4526(08)00401-4. PMID: 18772102.

42. Vassar R, Bennett BD, Babu-Khan S, Kahn S, Mendiaz EA, Denis P, Teplow DB, Ross S, Amarante P, Loeloff R, Luo Y, Fisher S, Fuller J, Edenson S, Lile J, Jarosinski MA, Biere AL, Curran E, Burgess T, Louis JC, Collins F, Treanor J, Rogers G, Citron M. Beta-secretase cleavage of Alzheimer's amyloid precursor protein by the transmembrane aspartic protease BACE. Science. 1999 Oct 
22;286(5440):735-41. doi: 10.1126/science. 286.5440.735. PMID: 10531052.

43. Ikonomovic MD, Mufson EJ, Wuu J, Bennett DA, DeKosky ST. Reduction of choline acetyltransferase activity in primary visual cortex in mild to moderate Alzheimer's disease. Arch Neurol. 2005 Mar;62(3):425-30. doi: 10.1001/archneur.62.3.425. PMID: 15767507.

44. Kim SF, Huri DA, Snyder SH. Inducible nitric oxide synthase binds, S-nitrosylates, and activates cyclooxygenase-2. Science. 2005 Dec 23;310(5756): 1966-70. doi: 10.1126/science. 1119407. PMID: 16373578 . 